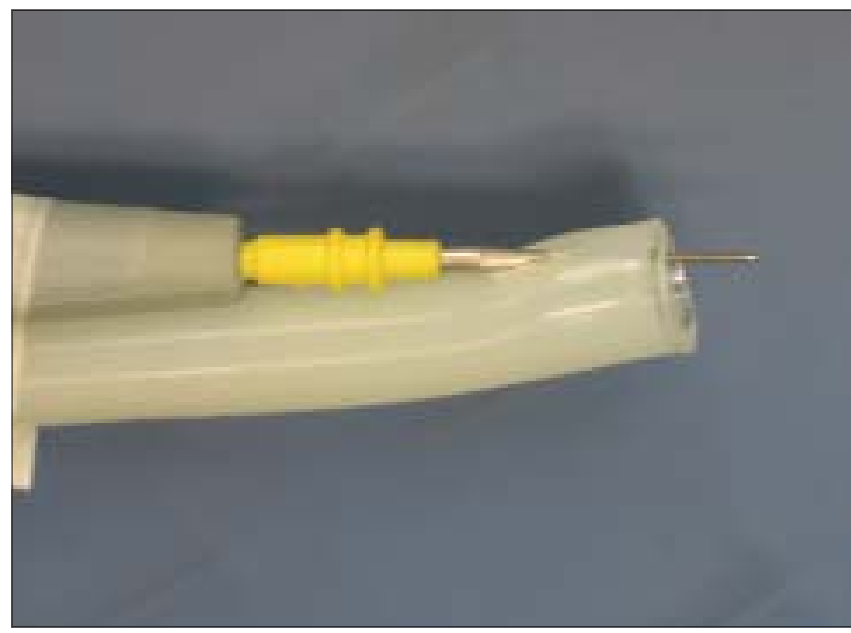

Figure 1: Close-up of tip

\title{
Suction diathermy
}

\section{Dear Sir,}

Electrocautery smoke is both mutagenic ${ }^{[1]}$ and can carry malignant cells and viable virus particles. ${ }^{[2]}$ Suction clearance of the diathermy plume has been recommended using commercially available systems. ${ }^{[3]}$ We describe a simple modification of standard theatre equipment that clears diathermy-generated smoke from the surgical field.

A needle point is attached to the standard handheld diathermy. A longitudinal slit is made $10 \mathrm{~mm}$ from the end of a piece of standard suction tubing. The diathermy needle is introduced through the tubing to project 6-7 $\mathrm{mm}$ from the end of the tube [Figure 1]. The suction tubing is then taped to the handheld diathermy with three steristrips, so the controls are free and allowing good visualization for surgeon and assistant [Figure 2].

Our standard technique for making incisions is to perform a subdermal infiltration with 0.5 or $1 \%$ lignocaine containing $1: 200,000$ adrenaline solution. After waiting for seven minutes to optimize the effect of the adrenaline, a No. 15 blade is used to incise the skin to deep dermal level.

The diathermy is set on coagulation mode and the tip lightly 'brushed' over the stretched tissues. With minimal charring the remaining dermis is divided and the subcutaneous fat is breached. The combination of a continual distraction tension and light brushing with

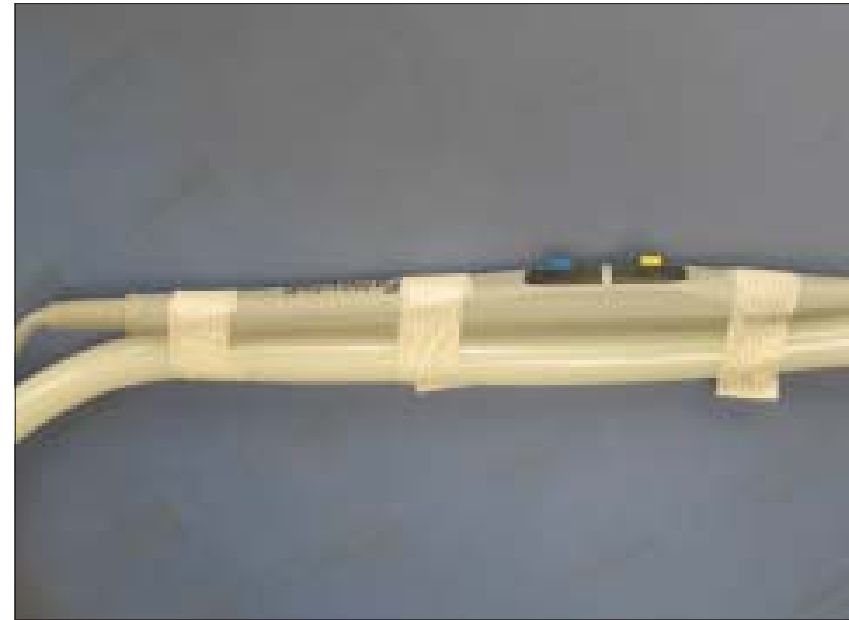

Figure 2: The suction-diathermy

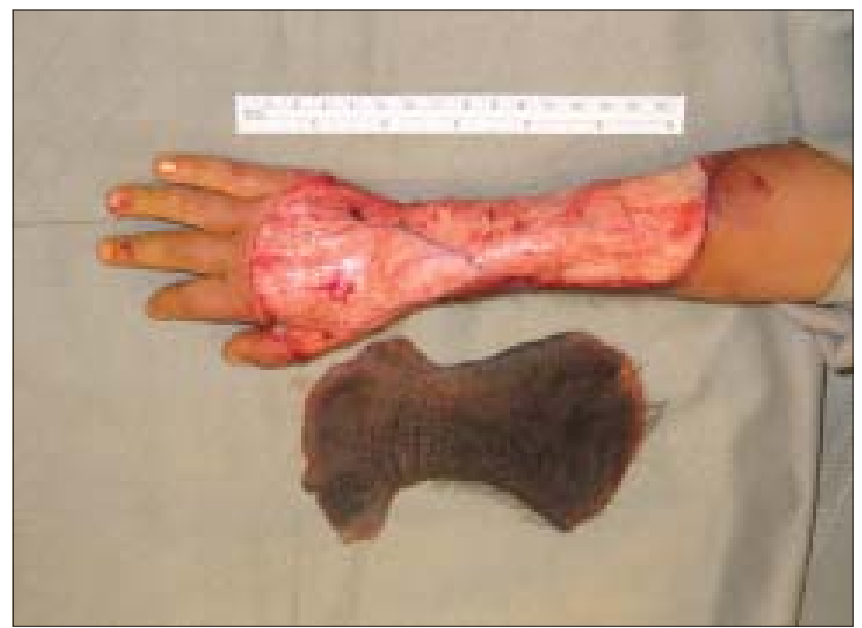

Figure 3: The excision bed following the removal of a giant hairy nevus. A tourniquet was not used as Integra ${ }^{\mathrm{TM}}$ is going to be used to resurface the defect and it is critical that no haematoma develops 
the diathermy needle using the coagulation mode can develop the incision in a bloodless fashion.

Figure 3 shows the excisional defect after removing a hairy naevus without tourniquet. Superficial nerves and veins have been preserved. We claim no novelty in our 'in house' system but commend it on the basis of ease of use, cost and efficacy.

\section{Samuel Chow Man Wai,} Ringo Chu Wing Hong, Andrew Burd

Division of Plastic, Reconstructive and Aesthetic Surgery, Department of Surgery, The Chinese University of Hong Kong, Prince of Wales Hospital, Hong Kong
Address for correspondence: Professor Andrew Burd, Division of Plastic, Reconstructive and Aesthetic Surgery, Department of Surgery, The Chinese University of Hong Kong, Prince of Wales Hospital, Hong Kong SAR. E-mail: andrewburd@surgery.cuhk.edu.hk

\section{REFERENCES}

1. Gatti JE, Bryant CJ, Noone RB, Murphy JB. The mutagenicity of electrocautery smoke. Plast Reconstr Surg 1992;89:781-6.

2. Fletcher JN, Mew D, DesCoteaux JG. Dissemination of melanoma cells within electrocautery plume. Am J Surg 1999; 178:57-9.

3. Pillinger SH, Delbridge L, Lewis DR. Randomized clinical trial of suction versus standard clearance of the diathermy plume. $\mathrm{Br} \mathrm{J}$ Surg 2003;90:1068-71. 